\title{
Çalışanların Çevresel Tutkusunun Yeşil Davranışları Üzerindeki Etkisi
}

\author{
Gökhan Akandere a
}

Özet

Araştırmanın temel konusu, spor ve sağlık hizmeti çalışanı 60 kadın ve 80 erkek katılımcının yeşil davranışlarının ve çevresel tutkularının birbirlerine olan etkisinin belirlenmesidir. Araştırma verileri demografik sorular ve yeşil davranış ve çevresel tutku ölçekleri aracılığıyla elde edildi. Elde edilen veriler açıklayıcı ve doğrulayıcı faktör analizine tabi tutulmuş ve doğrulanan model üzerinde çevresel tutkunun yeşil davranışa olan etkinin belirlenmesinde yapısal eşitlik modellemesi kullanılmıştır. Araştırmanın bulgularına göre, çevresel tutkunun yeşil davranışları yerine getirilmesinde önemli bir rol oynadığı ve üzerinde anlamlı ve olumlu etkiye sahip olduğu tespit edilmiştir. İşletmeler, çalışanların psikolojik ihtiyaçlarını karşılamak için yatırımlar, kişilerarası ve teknik iş becerilerini geliştirmek için eğitim yoluyla olumlu bir çalışma ortamı yaratabilecektir. Yine araştırma, bir çalışanın çevresel aktivizm, sürdürülebilirlik ve korunma konusunda olumlu duyguları varsa çevre yanlısı davranışlarını artırılabileceğini göstermektedir Sonuç olarak bu araştırma, çalışanların çevre yanlısı davranışlarının sonuçlarının açılanmasında çevresel tutkunun zorunlu rolünü göstererek literatüre katkıda sağlamaktadır.
Anahtar Kelimeler

Çevresel Tutku

Yeşil Davranış

Çevre Dostu Davranış

Yapısal Eşitlik Modellemesi

Makale Hakkında

Geliş Tarihi: 01.10.2019

Kabul Tarihi: 16.12.2019

Doi: $10.18026 /$ cbayarsos.628077

\section{Impact of Employees' Environmental Passion on Their Green Behaviors}

\section{Abstract}

The main subject of the research was to determine the effects of green behaviors and environmental passions of 60 female and 80 male participants who are sports and health service employees. The results of the research were obtained there demographic questions and scales of passion for green behavior and interpretation. The data obtained were subjected to descriptive and confirmatory factor analysis, and in the case where the effect of the current passion on green behavior was determined in the validated model, equality modeling is here. According to the findings of the research, we played something in our relationship with them and are sought by leaders; Businesses will be able to create a working environment for training by choosing investments, interpersonal and technical workers skills for employees' psychological teams. Again, research can enhance an employee's pro-behavior that surrounds positive emotions about maintaining, protecting and protecting. As a result, this study aims to investigate the literature by showing the compulsory role of passion while the results of the pro-environmental behaviors of the employees can be explained.
Keywords

Environmental Passion

Green Behavior

Eco-Friendly Behavior

Structural Equation Modeling

About Article

Received: 01.10.2019

Accepted: 16.12 .2019

Doi: $10.18026 /$ cbayarsos.628077

a Selçuk Üniversitesi Sosyal Bilimler Meslek Yüksekokulu Dr. Öğr. Gör., gakandere@selcuk.edu.tr, Orcid:0000-0002-5051-1154 


\section{Giriş}

İklim değişikliği, çevre ve insanlığın karşılaştığı en büyük risk oluşturan küresel bir sorundur. İnsan davranışı, sera gazı emisyonları, kirlilik ve doğal kaynakların hammadde ve enerji kullanımı nedeniyle birçok çevre sorununa neden olmaktadır. İşletmeler çevresel bozulma ve kirlenmenin uzun vadeli sonuçlarını ele almak ve duyarlılıklarını ve sorumluluklarını artırmak için baskı altındadır. Hükümetler işletmeleri çevresel mevzuat ve düzenlemelere uymaya zorlamaktadır. Küresel kuruluşlar, hem itibar hem de artan rekabet avantajı açısından çevresel sürdürülebilirliğe ilişkin yararları ve fırsatları kademeli olarak kabul etmiş ve daha sürdürülebilir çalışma faaliyetlerini benimsemeye başlamıştır (Darnall vd., 2008).

Ancak, yalnızca bu sistemleri benimsemek yetersizdir. İklim değişikliğinin büyük oranda insan faaliyetlerinden kaynaklandığı ve çevre programlarının başarısının çalışanların davranışlarına bağlı olduğu bilinmektedir (Daily vd., 2009). Çevre programlarının başarısı genellikle çalışanların davranışlarına bağlı olduğu göz önüne alındığında, çalışanları çevresel davranışlarda bulunmaya teşvik etmek günümüz küresel ekonomisinde işletmeler içim kritik bir öneme sahiptir.

Lamm vd., (2013) bu perspektifi, organizasyonların sürdürülebilirlik başarısının büyük ölçüde bireysel çabalara bağlı olduğunu iddia ederek desteklemektedir. Bu, stratejik girişimlerin bireysel çalışanların aktif desteği ve katılımı olmadan uygulanamayacağını göstermektedir. Bir bireyin kararının etkisi küçük görünebilir, ancak toplamda bu etki önemli olacaktır. İşyerinde geri dönüşüm, koruma ve atık azaltma davranışları gibi çevresel yanlı davranışları teşvik etmek, sadece kuruluşların yeşil imajlarına katkıda bulunmayacak, aynı zamanda iklim değişikliğini olumlu yönde etkileyecek ve daha fazla çevresel bozulmayı önleyecektir.

Birçok firma için, proaktif çevre yönetimine geçiş, sadece hükümetlerden değil, müşterilerden, çalışanlardan ve rakiplerden de gelen baskılar tarafından yönlendirilmektedir (Berry ve Rondinelli, 1998). Küresel işletmelerin yeşil kalkınma stratejisini geliştirme öncülügünde, gittikçe daha fazla sayıda çalışan, işverenlerinin aktif çevre uygulamalarını işletme süreçlerinde yerine getirilmesini giderek daha fazla talep etmektedir. Ulusal Çevre Yöneticileri Birliği (NAEM 2009) tarafından yapılan bir ankete göre katılımcıların \% 36'sının yeşil şirketler için çalışmamın kendileri için artı bir değer oluşturacağını düşündüklerini belirtilmektedir.

Çalışanların bakış açısına göre, kuruluşlarından alınan çevresel destek belki de kuruluşun doğal çevreyi korumalarına yardımcı olma taahhüdünün en iyi ifadesidir. Bir işletmecinin çevresel konularla ilgilenme değerleri ve kabiliyeti, çevresel kararlar vermesini ve uygulanmasını doğrudan belirler (Papagiannakis ve Lioukas, 2012). Sonuç olarak, bu yöneticiler sürdürülebilirlik puanlarını ve ekonomik rekabet edebilirliği arttırırken aynı zamanda kirlilik sorunlarına da eşzamanlı olarak çevresel çözümler aramaktadırlar (Porter ve Linde, 1995).

Genel olarak çalışanlar, işyerinde evde olduğu gibi aynı finansal ilgiye sahip değildir. Genellikle iş yerinde kullanılan cihazların enerji kullanımlarına dikkat etmeyebilirler (Carrico ve Riemer , 2011).

Literatürde, çalışanların işyerinde çevresel yanlı davranışlarını araştıran araştırma sayısı oldukça azdır. Araştırmada bu boşluğu doldurmaya ve çevresel tutkunun çalışanların işyerindeki yeşil davranışlarına etkisiyle kuruluşlar içinde çevresel yanlı davranışları geliştirmeye odaklanma çağrısına yanıt verilmeye çalışılmıştır. 
Çevre yanlısı davranış, yeşil davranış, geri dönüşüm, kaynakların rasyonel kullanımı, çevresel girişimlere katılım, daha sürdürülebilir politikalar gibi çevreye olabildiğince az zarar veren, çevreye yarar sağlayan ve işletmenin çevresel performansını artırabilecek bilinçli, bireysel ve isteğe bağlı/gönüllü sosyal davranışlar/iş yapma eylemleridir (Stern, 2000; Ramus ve Steger, 2000; Ramus ve Killner, 2007; Russell ve Griffiths, 2008; Boiral, 2009, Steg ve Vlek, 2009; De Roeck ve Farooq, 2017).

$\mathrm{Bu}$ bağlamda yeşil davranışın çevresel performansın önemli bir belirleyicisi olduğu varsayımı, çalışanların çevreye karşı sorumlu davranışlar gerçekleştirerek iş gereksinimlerinin ötesine geçtiği, kuruluşlarının çevresel verimliliğini geliştirmelerine yardımcı oldukları fikri olduğu söylenebilir.

Ayrıca literatürde çevresel işyeri davranışları, çevresel üretken işyeri davranışları (Ciocirlan, 2016), işyerinde çevre dostu davranış (Saifulina ve Carballo-Penela, 2017), çalışanların yeşil uygulamaları (Chan vd., 2014), sürdürülebilir çalışma tarzları (Greene vd., 2014) ve çevre yönetimi uygulamaları (Paille vd., 2013) yeni terimler kavramlaştırılmaktadır.

Yeşil davranış uygulamaları, işe yürüme (Adams vd., 2017), çevresel etkinliklere katılım (Tsai vd., 2016), yeşil konular hakkında meslektaşlarına yardımcı olma (Paille vd., 2016), enerji azaltma faaliyetleri (Lo vd., 2012b), geri dönüşüm, 1şıkları ve elektrikli aletleri kapatmak (Aizawa vd., 2008), seyahat etmek yerine video konferanslar yapmak, toplu taşıma araçlarını kullanmak (Gardner ve Abraham, 2010), yeniden kullanılabilir bardak ve şişelerden içmek gibi davranışlar (Tsai vd., 2016), su ve enerji tasarrufu hakkında bilinçlendirmek, israfı azaltmaya teşvik etmek, çevresel konular, küresel ısınma riski ve iş ortamının faaliyetlerinin etkilerini nasıl azaltabileceği hakkında eğitim programları geliştirmek, kağıtları çift taraflı yazdırarak kullanmak (Fu vd., 2017), atık yönetimi (Liu vd., 2017), enerji tüketimi (Berardi, 2017), yeşil ürünlerin satın alınması (Ramayah vd., 2010) gibi faaliyetleri kapsamaktadır.

Bir çalışanın işyerindeki yeşil davranış, geri dönüşüm, atık yönetimi, enerji tüketiminde azalma veya bilinçli olarak eylemlerinin çevre üzerindeki olumsuz etkisini en aza indirmeyi amaçlayan diğer davranışlar gibi uygulamaları içerir (Wang vd., 2016). Bireysel düzeyde bu faaliyetler önemsiz gibi görünse de, bir kurumun genel çevresel performansı üzerinde büyük bir kümülatif etki oluşturabilir.

Erbaşı (2019), yeşil davranış ölçeği geliştirmeye yönelik yapmış olduğu araştırmada, yeşil davranış boyutlarını, çevresel duyarlılık, çevresel katılım, ekonomik duyarlılık, yeşil satın alma, teknolojik duyarlılık olarak beş boyutta değerlendirmiştir. Literatürde yer alan yeşil davranışların temel olarak boyutları aşağıdaki gibidir (Barr vd., 2003, Ramus ve Killmer 2007, Sun vd., 2012, Asilsoy, 2012; Lopez-Mosquera vd., 2015; Asilsoy ve Oktay, 2016; Asilsoy ve Oktay, 2018):

-Enerji tasarrufu: daha fazla 1sıtma yerine daha fazla kıyafet kullanma, yüksek verimli ampuller kullanma, binalar için çift camlı pencereler kullanma, enerji tasarruflu cihazlar ve beyaz eşya kullanma, sıcak su sıcaklığını düşürme, enerjiyi korumak için ısıtmayı düşük tutma, lambaları kapatma ve azaltma, kullanılmayan odalarda isı ve bina izolasyonu,

- Su tasarrufu: alınan banyo ve duş sayısını azaltma, banyo yerine duş alma, sabunlamada muslukları kapatma, bulaşıkları yıkarken muslukları kapatma, dişleri fırçalarken muslukları kapatma, daha az suya ihtiyaç duyan bitkileri kullanma, sifon ve benzeri sistemlerde su kullanımı azaltma,

-Atık yönetimi: kağıtları yeniden kullanma, pil kullanımını azaltma, plastik şişeleri geri dönüştürme, bahçe atıklarını kompost etme, teneke kutu geri dönüşümü, cam ve kağıtları 
geri dönüştürme, camı yeniden kullanma, mobilya ve giysileri bağışlama,

- Çalışan katılımı: çevresel karar alma sürecine katılım, çevre kampanyalarına katılım, çevre aktivisti ve benzeri davranışlar,

-Sürdürülebilir ulaşım: araba yerine toplu taşıma araçlarını kullanmak, kısa mesafeleri yürümek, araba kullanmak yerine bisiklet kullanmak,

-Yeşil tüketim: alışveriş için kendi çantasını kullanmak, yerel olarak üretilen yiyecekleri satın almak, geri dönüştürülmüş tuvalet kağıdı satın almak, daha az paketlenmiş ürünler satın almak, organik ürünler satın almak, aerosol ve toksik deterjan kullanmaktan kaçınmak, geri dönüştürülmüş kağıt almak, yerel bir mağazadan satın almak,

Ren vd., (2017), yeşil insan kaynakları yönetimi stratejilerinin, çalışanların çevreye yönelik isteğe bağlı davranışlarını motive edebileceğini iddia etmektedir. Yöneticiler bu stratejilerle, çalışanlarla yakın ilişkiler kurar, çevresel değerleri yayar, çevresel davranışları modeller ve çalışanları işyerinde çevreye duyarlı davranışlar geliştirmeye teşvik eder (Robertson ve Baring, 2013).

Blok vd., (2015), kamu sektöründe (yeşil üniversite), liderlerin yeşil davranışları destekleyerek çalışanların yeşil davranışlarını etkileyebileceği sonucuna varmıştır. Bu bağlamda, çevre için algılanan örgütsel desteğin ve çevresel/yeşil davranış ile pozitif ilişkili olduğunu göstermektedir (Lamm vd., 2015; Temminck vd., 2015). Çalışanların kurumları tarafından desteklendiklerini düşündüklerinde ve çevresel davranışların yararını anladıklarında, çevreye karşı sorumlu davranmaya daha yatkın olacaktır (Alt ve Spitzeck, 2016).

Çalışanların çevre eğitimi, ülkelerin (Gunasekaran ve Gallear, 2012) ve işletmelerin (Wagner, 2011) çevre uyumluluğunu artırmak için kullandıkları önemli bir uygulamadır. Örneğin, Meksika, Almanya, Amerika Birleşik Devletleri, Hindistan gibi gelişmiş ülkeler, iş planlaması ve karar vermede aynı anda ekonomik büyüme, çevre koruma ve sosyal eşitliği içerecek şekilde tasarlanmış Sürdürülebilir Kalkınma ve Çevre Eğitimi programları uygulamaktadır (Daily vd., 2012).

Çevresel faaliyetler için eğitim, çalışanların gönüllü davranmalarını ve çevresel değerlerin yayılmasını teşvik eder (Boiral, 2009). Özellikle, bu strateji çalışanlara yeşil bilgi ve becerileri aktarmaya, olumsuz çevresel etkileri anlamaya ve en aza indirgemeye yardımcı olmaktadır. Böylece işletmeler, çalışanların çevresel sorunları tanıma yeteneğini arttırmaktadır.

Bu bağlamda eğitim programları çok çeşitli ve teknik bilgilerin iletilmesi, sosyalleşme, yeni fikirlerin kabulü gibi birçok amaca sahip olduğu söylenebilmektedir.

Sarkis vd., (2010) eko tasarım metodolojileri ve teknikleri, yaşam döngüsü değerlendirmesi, malzemelerin geri dönüşümü ve yeniden kullanımı ve atıkların atılması gibi çevresel eğitim örnekleri sunmaktadır. Çevresel inisiyatifleri yaymak isteyen kuruluşlar için Sarkis vd., (2010) çevresel eğitim programlarının yeni zihniyetin sağlanmasına yardımcı olabileceğini ve çalışanların yeni eko-fikirler ve davranışlar üretmelerine yardımcı olması için odaklanmaları gerektiğini savunmaktadır. Son olarak, Sarkis vd., (2010) eğitimin kurum içindeki tüm çalışanların karar alma yeteneklerini geliştirmek için güçlü bir yol sunduğunu belirtmektedir.

Yöneticilerin çevreye yönelik yapılan uygulamalarla ilgi geri bildirim yapması, çalışanların bilgi, beceri ve yeteneklerini arttırmaya yardımcı olacaktır (Masri ve Jaaron, 2017). Bu da çalışanların çevresel sorumluluk alma konusundaki motivasyonlarını artırabilir (Govindarajulu ve Daily, 2004). Bu nedenle, çalışanların çevresel performanslarını ve faaliyetlerini izlemek ve değerlendirmek, çalışanların çevre hakkında net bilgi edinmelerine, yeşil gönüllü davranışları benimsemelerine yardımcı olabilecektir (Pinzone vd., 2016). 
Pinzone vd., (2016), çalışanların gönüllü eko davranışlarının iyileştirilmesinde çevresel faaliyetlerin, beceri ve yetkinliklerin değerlendirilmesinin önemini vurgulamaktadır.

Bir diğer önemli yeşil uygulama da yeşil çalışanların katılımıyla yeşil ekipler oluşturmaktır. Yeşil ekipler, çalışanlara proaktif kirlilik önleme çabalarına aktif olarak katkıda bulunmaları için ilham verecektir (Govindarajulu ve Daily, 2004). Ayrıca, çalışanların çevre sorunlarıyla ilgili karar ve önerilerde bulunmalarına izin verilirse, çevresel faaliyetlerde gönüllü olarak yer almaya daha istekli olabileceklerdir (Pinzone vd., 2016). Bu bağlamda işletmeler çalışanlarını yeşil davranışlara teşvik etmek için, çalışan katılımını teşvik etmeleri gerekmektir. Çalışanlar şirketlerini çevre dostu programlara katılıyor olarak algıladıklarında, çevresel olarak olumlu davranış sergileme olasılığı da artmaktadır (Raineri ve Paille, 2016).

Yüksek düzeyde kurumsal güven ve çalışan refahının, çalışanların işyerinde destekleyici yeşil davranışlarda bulunma olasılığını artırabileceğini tespit edilmiştir. Ayrıca, daha olumlu bir refah duygusunun, çalışanların işyerinde yeşil davranışlarda bulunma olasılıklarının daha yüksek olması ile ilişkili olduğunu göstermektedir (Danna ve Griffin, 1999).

İşletmeler iyi gelişmiş bir ödüllendirme yapısıyla, çevre konularında çalışanların katkılarına değer verdiklerini ve çalışanların bireysel ve gönüllü olarak çevre sorunlarına yenilikçi çözümler bulmalarını sağlayabilmektedir. Sonuç olarak, işletmenin çevresel hedefleriyle tutarlı bir şekilde hareket etmek için ödüllendirilen çalışanların, yönetimin yeşil davranışı desteklediğini algıladıkları görülmektedir.

Çevresel tutku, bireyin kontrolü altında kalan ve tutkunun hedefi olan aktivite veya ilişkide bulunma motivasyonu ile sonuçlanan olumlu bir duyguyu yansitır (Vallerand vd., 2007). Çevre tutkusu, çevre yanlısı davranışlarda bulunmak isteyen bireylerin sahip olduğu olumlu bir duygu ve çevreyi iyileştirme davranışlarında bulunma olarak tanımlanmaktadır (Robertson ve Barling, 2013).

Çevresel tutkunu sahip çalışanların, çevre yanlısı davranışlarda bulunduğunu gösteren nedenler bulunmaktadır. Birincisi, çevre tutkusu, çevreyi korumaya katkıda bulunarak bir fark yaratma konusunda enerji, olumlu duygular ve ilham dolu bir deneyimdir (Vallerand vd., 2003). Bu deneyimle, çevre tutkusu olan ve kendini tanımlayan çevre dostu eylemlere dönüşür. (Vallerand vd., 2007). İkincisi, çevresel tutku ahlaki bir davranış olduğundan, ahlaki davranış çevre yanlısı davranışı etkilemektedir (Stern, 2000). Üçüncüsü, çevresel tutku olumlu bir duygu oluğundan, önceki çalışmaların önerdiği gibi olumlu duygular bir çalışanın çevresel davranışını etkilemektedir (Robertson ve Barling, 2013). Çevresel tutkusu bir fark yaratmak bağlamında, çevre yanlısı faaliyetleri tetikleyecektir.

Hipotez 1: Çalışanların çevresel tutkuları, yeşil davranışlarını etkilemektedir.

\section{Yöntem}

Araştırmanın temel konusu, çalışanların yeşil davranışlarının ve çevresel tutkularının ilişkisinin incelenmesidir. Ayrıca yeşil davranış ve çevresel tutku değişkenlerinin birbirlerine olan etkinin belirlenmesi amaçlanmıştır. Araştırmaya Spor ve sağlık hizmeti çalışanı 60 kadın ve 80 erkek dahil edilmiştir. Araştırma evreninden örneklem ölçüt örnekleme yöntemiyle belirlenmiştir. Bu araştırma betimsel tarama modelinde desteklendi. Araştırma verileri demografik sorular ve yeşil davranış ve çevresel tutku ölçekleri aracılığıyla elde edildi. Elde edilen verilerin analizinde yeşil davranış ve çevresel tutku ölçekleri açıklayıcı ve doğrulayıcı faktör analizi uygulanmış ve çevresel tutkunun yeşil davranışa olan etkisi yapısal eşitlik model ve path analiziyle tespit edilmiştir. Araştırmanın örneklemi Konya ilinde 
bulunan spor ve sağlık merkezinde çalışan personelden oluşmaktadır.

\section{Araştırmanın Modeli}

Geliştirilen model, çalışanların çevreye karşı olan tutkularının işyeri yeşil davranışlarını nasıl etkilediğine dairdir. Şekil 1'de araştırmada önerilen model gösterilmiştir.

\section{Şekil 1. Önerilen Model}

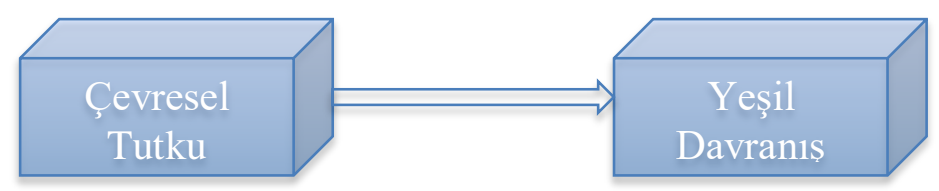

\section{Veri Toplama Aract}

Çalışanların yeşil davranışlarını ölçmek için Ramus ve Steger (2000), Whitmarsh ve O'Neill (2010), Robertson ve Barling (2013), Chou (2014), Blok vd., (2015), Leygue vd., (2017), Wesselink vd., (2017), Ratliff vd., (2017), Phama vd., (2019) ve Paille ve MeijaMorelos (2019) tarafından geliştirilen 20 maddeden oluşan ölçek kullanılmıştır. Ölçek soruları, her biri 5 puanlık bir ölçekte derecelendirilen değerlere (1= kesinlikle katılmıyorum, 5 = kesinlikle katılıyorum) göre cevaplanmaktadır. Çalışanların çevresel tutkusunu ölçmek için Robertson ve Barling (2013) geliştirdiği 10 maddelik ölçek kullanılmıştır. Ölçek soruları, her biri 5 puanlık bir ölçekte derecelendirilen değerlere $(1=$ kesinlikle katılmiyorum, 5=kesinlikle katılıyorum) göre cevaplanmaktadir.

\section{Verilerin Analizi}

Spor ve sağlık hizmeti işletmeleri çalışanlarının çevresel tutkularının yeşil davranışları üzerine etkisini belirlenmesinin amaçlandığı bu çalışmada veriler anket yoluyla 140 katılımcıdan elde edilmiştir. Bu amaç doğrultusunda kullanılacak olan çevresel tutku ve yeşil davranış ölçekleri için geçerlilik ve güvenilirlik analizleri sırasıyla elde edilen verinin literatüre uygun teorik yapılar dikkate alınarak açıklayıcı faktör analizi, doğrulayıcı faktör analizi ve Cronbach alpha katsayıları yardımıyla gerçekleştirilmiştir. Geçerlilik ve güvenilirliği sağlanan ölçeklerin aralarındaki ilişkiler ve etkiler Pearson korelasyon katsayısı, yapısal eşitlik modellemesi ve path analizi yardımıyla test edilmiştir. İstatiksel analizler uygulanmadan önce verilerin normalliği için çarpıklık, basıklık katsayıları, PP-Plot grafikleri ve Anderson Darling normallik testi kullanılmış ve ayrıca gruplardaki örnek hacimlerin 30'un üzerinde olması durumunda da merkezi limit teoremi gereği parametrik testler uygulanmıştır. Bununla birlikte varyansların homojenliği Levene homojenlik testiyle kontrol edilmiştir. Katılımcılara ilişkin demografik özellikler ortalama, standart sapma, frekans ve yüzde olarak tablolarda sunulmuştur. İstatiksel analizlerde anlamlılık için $\mathrm{p}<0,05$ değeri kullanılmıştır.

\section{Bulgular}

Araştırmaya katılan çalışanların demografik bilgileri Tablo 1'de gösterilmiştir. 
Tablo 1. Katılımcıların Demografik Bilgileri

\begin{tabular}{lcc}
\hline & Frekans (n) & Yüzde (\%) \\
\hline Yas & 8 & 5,7 \\
$20-23$ yaş arası & 20 & 14,3 \\
$24-27$ yaş arası & 45 & 32,1 \\
$28-31$ yaş arası & 67 & 47,9 \\
32 yaş ve üstü & & \\
Cinsiyet & 80 & 57,1 \\
Erkek & 60 & 42,9 \\
Kadın & & 42,1 \\
Medeni Durum & 59 & 57,9 \\
Bekar & 81 & 17,9 \\
Evli & & 13,6 \\
Ĕgitim Durumu & 25 & 32,1 \\
İlkokul & 19 & 30 \\
Ortaokul & 45 & 6,4 \\
Lise & 42 & $\mathbf{1 0 0}$ \\
Lisans & 9 & \\
Lisansüstü & $\mathbf{1 4 0}$ & \\
Toplam & & \\
\hline
\end{tabular}

Yeşil davranış ve çevre tutkusu ölçeklerinin güvenilirliğini tespit etmede kullanılan Cronbach's Alpha katsayıları, örneklem büyüklüğünün yeterli olup olmadığını belirlemek için kullanılan KMO değerleri incelenmiştir. Tablo 2'de yeşil davranış ve çevre tutkusu ölçeklerinin Cronbach's Alpha katsayısı, ortalaması, KMO ve Bartlett değerleri belirtilmiştir.

Tablo 2. Yeşil Davranış ve Çevresel Tutku Düzeyi

\begin{tabular}{lccccccc}
\hline Ölçekler & $\begin{array}{c}\text { Cronbach's } \\
\text { Alpha }\end{array}$ & Ort. & S.H. & $\begin{array}{c}\text { Madde } \\
\text { Sayısı }\end{array}$ & KMO & Bartlett & p \\
\hline Yeşil Davranış & 0,907 & 4,27 & 0,56 & 16 & 0,882 & 1002,198 & $<0,001$ \\
Çevresel Tutku & 0,904 & 4,44 & 0,55 & 9 & 0,866 & 748,009 & $<0,001$ \\
\hline
\end{tabular}

Yeşil davranış ölçeğinin güvenilirliğini tespit etmede kullanılan Cronbach's Alpha katsayısı $(0,907)$ ve güvenlik ikliminin Cronbach's Alpha katsayısı $(0,904)$ olarak elde edilmiştir. Bu katsayıya göre, ölçeklerin içsel tutarlılığı sağlanmıştır ve ölçeklerin yeteri derecede güvenilir olduğu tespit edilmiştir.

Ayrıca Tablo 2' de ölçeğin ilişkin tanımlayıcı istatistikler ve yapısal geçerliliği tespit etmede kullanılan açıklayıcı faktör analizine ilişkin varsayımlar yer almaktadır. Elde edilen bulgulara göre, yeşil davranış ölçeğinin ortalaması $(4,27)$ ve çevresel tutku ölçeğinin 
ortalaması $(4,44)$ olarak bulunmuştur. Ölçeklerin açıklayıcı faktör analizi sonucunda, yeşil davranış 16 ve çevresel tutku 9 maddeden oluşmuştur. Açıklayıcı faktör analizi uygulanırken faktör yükü 0,5'in altında kalan ölçek maddeleri analiz dışı bırakılmıştır.

Açıklayıcı faktör analizi varsayımlarından, örneklem büyüklügünün yeterli olup olmadığını belirlemek için kullanılan KMO testine göre, yeşil davranış faktör değeri $(0,882)$ ve çevresel tutku faktör değeri $(0,866)$ olarak bulunmuş ve örneklem büyüklüklerinin yeterli olduğu belirlenmiştir. Bununla birlikte, Bartlett küresellik testi sonucunda da, ölçekler için anlamlı sonuç elde edilmiş ve ölçeklerin açıklayıcı faktör analizi ile irdelenmesinin uygun olduğu tespit edilmiştir. Tablo 3'de Çevresel Tutku ölçeğinin açılayıcı faktör analizi sonuçları ve düzeyi gösterilmiştir.

Tablo 3. Çevresel Tutku Ölçeğinin Açıklayıcı Faktör Analizi ve Düzeyi

\begin{tabular}{|c|c|c|c|c|c|}
\hline $\begin{array}{c}\text { Öz } \\
\text { değerler }\end{array}$ & $\begin{array}{c}\text { VA } \\
\text { Yüzdesi }\end{array}$ & $\begin{array}{c}\text { Kümülatif } \\
\text { VA } \\
\text { Yüzdesi }\end{array}$ & $\begin{array}{l}\text { Faktör } \\
\text { Yükleri }\end{array}$ & Ort. & S.H. \\
\hline \multicolumn{6}{|l|}{ Çevresel Tutku $(\alpha=0,904$, Ort $=4,44)$} \\
\hline 6,500 & 68,330 & 68,330 & 1 & & \\
\hline \multicolumn{3}{|l|}{ Çevresel konulara karşı tutkuluyum. } & 0,630 & 4,44 & 0,73 \\
\hline \multicolumn{3}{|l|}{ Çevre dostu davranışları uygulamaktan hoşlanırım. } & 0,744 & 4,49 & 0,73 \\
\hline \multicolumn{3}{|l|}{ Çevre dostu davranışlarla meşgul olmaktan hoşlanırım. } & 0,768 & 4,41 & 0,76 \\
\hline \multicolumn{3}{|l|}{ Çevreye faydalı olmaktan gurur duyarım. } & 0,789 & 4,49 & 0,67 \\
\hline \multicolumn{3}{|l|}{ Başkaları ile çevresel konuları zevkle tartışırım. } & 0,772 & 4,41 & 0,70 \\
\hline \multicolumn{3}{|l|}{ Çevreyi korumaktan zevk alırım. } & 0,819 & 4,47 & 0,70 \\
\hline \multicolumn{3}{|c|}{ Başkalarını daha fazla çevreye duyarlı olmaları için teşvik ederim. } & 0,773 & 4,37 & 0,76 \\
\hline \multicolumn{3}{|c|}{$\begin{array}{l}\text { Çevreye yardımcı olmak için gönüllü olarak zaman ayırdım ya da para } \\
\text { harcadım. }\end{array}$} & 0,730 & 4,47 & 0,79 \\
\hline \multicolumn{3}{|l|}{ Çevre değerlerim konusunda kendimi güçlü hissederim. } & 0,747 & 4,42 & 0,75 \\
\hline
\end{tabular}

KMO = 0,866; Bartlett Küresellik testi $=748,009, p<0,001$

Çevresel tutku ölçeğinin ilişkin güvenilirlik katsayısı $(0,904)$, faktör ortalaması $(4,44)$, öz değeri $(6,500)$, varyans açıklama yüzdesi $(68,330)$ olarak bulunmuştur. Tablo 3'de yeşil yönetim ölçeği sorularının ortalamaları ve standart sapmaları verilmiştir. Tablo 4 'de Yeşil Davranış ölçeğinin açıklayıcı faktör analizi sonuçları ve düzeyi gösterilmiştir. 
Tablo 4. Yeşil Davranış Ölçeğinin Açıklayıcı Faktör Analizi ve Düzeyi

\begin{tabular}{|c|c|c|c|c|c|}
\hline Faktör/Maddeler & $\begin{array}{c}\text { VA } \\
\text { Yüzdesi }\end{array}$ & $\begin{array}{l}\text { KümülatifVA } \\
\text { Yüzdesi }\end{array}$ & $\begin{array}{l}\text { Faktör } \\
\text { Yükleri }\end{array}$ & Ort. & S.H. \\
\hline \multicolumn{6}{|l|}{ Yeşil Davranış $(\alpha=0,907$, Ort $=4,27)$} \\
\hline 6,475 & 73,221 & 73,221 & 1 & & \\
\hline \multicolumn{3}{|c|}{ İşyerinde gereksiz yanan ampul gördüğümde hemen söndürürüm. } & 0,630 & 4,12 & 1,00 \\
\hline \multicolumn{3}{|c|}{$\begin{array}{l}\text { Geri dönüştürülebilir malzemeleri (kağıt, cam, metal, plastik, şişe, pil gibi) } \\
\text { geri dönüşüm kutusuna atarım veya başka bir amaçla kullanmak için } \\
\text { ayırırım. }\end{array}$} & 0,636 & 4,15 & 0,93 \\
\hline \multicolumn{3}{|c|}{ İşyerinde çevre dostu faaliyetlere katılırım (ağaç dikimi, bitki sulama) } & 0,736 & 4,12 & 0,89 \\
\hline \multicolumn{3}{|c|}{ Çıktı alırken ya da fotokopi çekerken kağıdı çift taraflı kullanırım. } & 0,726 & 4,19 & 0,83 \\
\hline \multicolumn{3}{|c|}{ Geri dönüştürülemeyen malzemeleri (çöp) organik atık kutusuna atarım. } & 0,672 & 4,23 & 0,84 \\
\hline \multicolumn{3}{|c|}{ İşe gidip gelirken toplu taşıma araçları/bisiklet kullanırım veya yürürüm. } & 0,819 & 4,17 & 0,95 \\
\hline \multicolumn{3}{|c|}{$\begin{array}{l}\text { İşyerindeyken plastik şişeyle su tüketimi yapmam, sebil ya da su matarası } \\
\text { kullanırım. }\end{array}$} & 0,651 & 4,20 & 0,89 \\
\hline \multicolumn{3}{|c|}{ İş arkadaşlarımı çevre dostu davranışlarda bulunmaya özendiririm. } & 0,587 & 4,24 & 0,84 \\
\hline \multicolumn{3}{|c|}{ Artan kağıtları atmam, bir şekilde (not tutmak vb. amaçlarla) kullanırım. } & 0,675 & 4,33 & 0,81 \\
\hline \multicolumn{3}{|c|}{ Mümkün olduğunda klima yerine camları açarak serinlemeyi tercih ederim. } & 0,664 & 4,35 & 0,79 \\
\hline \multicolumn{3}{|c|}{$\begin{array}{l}\text { İşyerindeki elektronik aletleri kullanmadığımda güç tasarrufu/uyku moduna } \\
\text { alırım, kapatırım veya fişi çekerim. }\end{array}$} & 0,725 & 4,35 & 0,84 \\
\hline \multicolumn{3}{|c|}{$\begin{array}{l}\text { Pil kullanımı gerektiren ofis malzemelerinde, şarj edilebilir piller tercih } \\
\text { ederim. }\end{array}$} & 0,658 & 4,40 & 0,76 \\
\hline \multicolumn{3}{|c|}{$\begin{array}{l}\text { Yöneticilerime veya işletme sahiplerine çevre dostu uygulamalar hakkında } \\
\text { önerilerde bulunurum. }\end{array}$} & 0,648 & 4,40 & 0,82 \\
\hline \multicolumn{3}{|l|}{ İş yerindeki çevre kuralarına uyarım. } & 0,732 & 4,29 & 0,87 \\
\hline \multicolumn{3}{|l|}{ İşyerinde sıcaklığa uygun giyinirim. } & 0,607 & 4,46 & 0,81 \\
\hline \multicolumn{3}{|c|}{$\begin{array}{l}\text { Müşterileri çevre dostu ürünlere ve çevreye duyarlı davranışlara } \\
\text { yönlendiririm. }\end{array}$} & 0,688 & 4,37 & 0,86 \\
\hline
\end{tabular}

KMO = 0,882; Bartlett Küresellik testi= 1002,198, p<0,001

Yeşil davranış ölçeğinin ilişkin güvenilirlik katsayısı $(0,907)$, faktör ortalaması $(4,27)$, öz değeri $(6,475)$, varyans açıklama yüzdesi $(73,221)$ olarak bulunmuştur. Tablo 4'de yeşil davranış ölçeği sorularının ortalamaları ve standart sapmaları verilmiştir. Tablo 5 'te değişkenler arası korelasyon matrisi gösterilmiştir. 
Tablo 5. Değişkenler Arası Korelasyon Matrisi

\begin{tabular}{ccccc}
\hline Ölçekler & Ort. & S.H. & ÇT & YÖD \\
\hline Çevresel Tutku & 4,27 & 0,56 & - & $0,679^{* * * *}$ \\
Yeşil Davranış & 4,44 & 0,55 & & - \\
\hline
\end{tabular}

Tablo 5'ten elde edilen bulgulara göre yeşil yönetimi uygulamaları ile güvenlik iklimi uygulamaları arasında pozitif ve istatistiksel bakımdan anlamlı ilişki bulunduğu belirlenmiştir. Tablo $6^{\prime}$ yapısal eşitlik modeli için gerekli olan uyum endeksi ve araştırma modelinin değerleri gösterilmiştir.

Tablo 6. Model Uyum Endeksi

\begin{tabular}{cccccccc}
\hline & $\chi 2 / \mathrm{df}$ & GFI & RMSEA & CFI & TLI & IFI & RMR \\
\hline Standard & $<3$ & $>0.90$ & $<0.08$ & $>0.90$ & $>0.90$ & $>0.90$ & $<0.08$ \\
Model & 1,839 & 0,930 & 0,070 & 0,920 & 0,913 & 0,941 & 0,042 \\
\hline
\end{tabular}

Х2: Ki kare (CMIN) df: Degrees of Freedom; RMSEA: Root Mean Square Error of Approximation; CFI: Comparative Fit Index; GFI: Goodness of Fit Index; RMR: Root Mean Square Residual; IFI: Incremental Fit Index

AMOS 23.0, anketin yakınsama ve ayırt edici geçerliliğini değerlendirmek için anket üzerinde doğrulayıcı faktör analizi yapmak için kullanılmıştır.

Doğrulayıcı faktör analizi sonuçları (Tablo 6), her ölçüm maddesine yüklenen faktör yükünün> 0.5 olduğunu ve uygunluk göstergelerinin gereksinimleri karşıladığını belirlenmiştir (Bagozzi ve Yi, 1988): $(\chi 2 / \mathrm{df}=1.839(<3), \mathrm{CFI}=0.920(>0.9)$, RMSEA $=0.070$ $(<0.08)$, TLI $=0.913(>0.9)$ ve GFI $=0.930(>0.9)$. Araştırmada kullanılan ölçeklerin son hali, yeşil davranış 11 madde ve çevresel tutku 9 madde olarak modelde değerlendirilmiştir. Faktör yükleri 0.5 altında olan maddeler değerlendirilmeden çıkartılmıştır.

Elde edilen sonuçlara dayanarak, analiz sonuçlarının ölçülen maddelerin makul bir geçerlilik ve güvenilirlik seviyesinde olduğu doğrulanmıştır. Dolayısıyla, açıklayıcı faktör analizi ile bulunan yeşil davranış ve çevresel tutku ölçeklerinin geçerliliği, doğrulayıcı faktör analizi ile de teyit edilmiştir. 


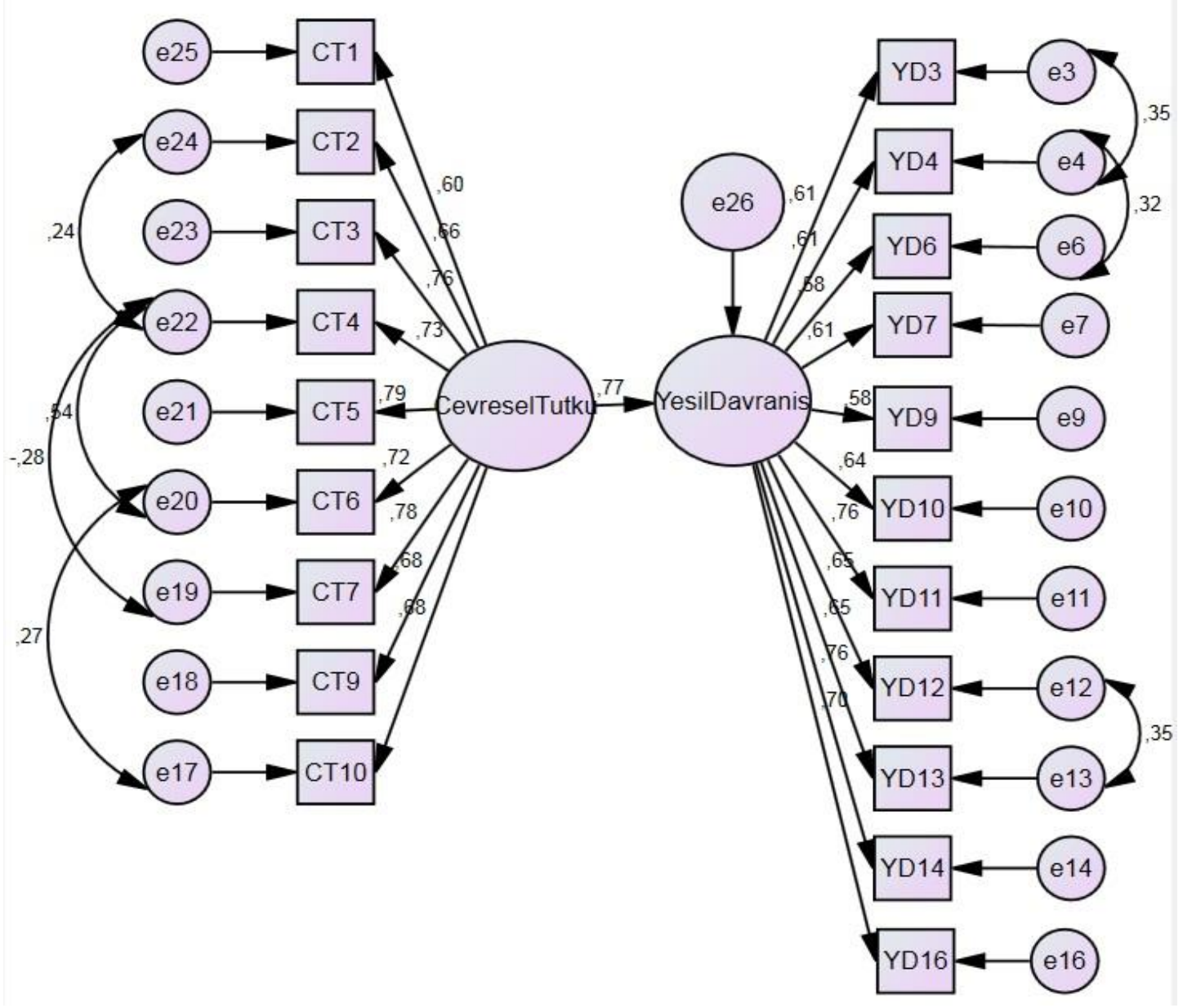

Modeldeki değişkenler arasındaki nedensel ilişkiler her bir değişken için istatistiksel olarak anlamlı bulunmuştur. Modelin analizi sonucunda yeşil davranışa ilişkin YD1, YD2, YD5, YD8 ve YD15 kritik oran değeri (t-değeri)'nin kabul edilebilir düzeyde olmaması nedeniyle analiz dışı bırakılarak model tekrar test edilmiştir. Modelin son hali Şekil 2'de gösterilmiştir. Tablo 7'de modele ilişkin standardize edilmemiş ve standardize edilmiş regresyon katsayısı, standart hata ve kritik oran yer almaktadır.

Tablo 7. Yapısal Eşitlik Modeline İlişkin Regresyon Matrisi ve R2 Değerleri

\begin{tabular}{ccccccc}
\hline Değişkenler & $\mathrm{B}$ & $\beta$ & Sh & $\mathrm{t}$ & $\mathrm{R}^{2}$ & $\mathrm{P}$ \\
\hline Çevre Tutku $\rightarrow$ Yeşil Davranış & 0,827 & 0,771 & 0,142 & 5,844 & 0,457 & $* * *$ \\
\hline
\end{tabular}

Tablo 7 'de gösterildiği gibi, çevresel tutkunun $(\beta=0,77, p<0,001, H 1)$ yeşil davranış üzerinde anlamlı ve olumlu etkiye sahiptir. Robertson ve Barling (2013), Afsar vd., (2016) ve Junot vd., (2017) önceki çalışmalarla tutarlı olarak çevresel tutkunun yeşil davranışları yerine getirilmesinde önemli bir rol oynadığı tespit edilmiştir. $\mathrm{Bu}$ sonuçlara göre $\mathrm{H} 1$ desteklenmiştir. 


\section{Tartışma, Sonuç ve Öneriler}

İşletmeler, çevresel performansı arttırmak için çalışanların yeşil davranışa dahil olmaları, özellikle çevre yanlısı davranışları yerine getirmeleri oldukça önemlidir. Çünkü böyle bir davranış çevresel sorunların üstesinden gelmeye ve kuruluşların sürdürülebilir kalkınmasını geliştirmeye katkıda bulunacaktır.

Literatürde işletmelere yönelik yapılan ilk çalışmalar, çalışanların çevresel davranışlarının evdeki çevre davranışlarına benzer olacağını varsaymasına rağmen, Andersson vd., (2005), kuruluşlardaki çevresel yanlı davranışın belirleyicilerinin diğerlerinin belirleyicilerinden farklı olduğunu vurgulamaktadır. Genel olarak, çalışanlar işyerinde, evdekilerle aynı finansal ilgiye sahip değildir. Çalışanlar tipik olarak enerji kullanımları ile ilgilenmezler ve ne kadar enerji harcadıkları konusunda çok az bağdaşırlar çünkü cihazlar genellikle birden fazla çalışan tarafından paylaşılır (Carrico ve Riemer, 2011). Ancak araştırmamızda çevresel tutkunun yüksek olduğu çalışanların, çevre ve işyeri yanlısı davranışlara doğrudan uyumlu olduğunu belirlemiştir (Tablo $7, \beta=0,771$ ). Örgütler, çevre dostu davranışları harekete geçirmek için liderleri ve çalışanları teşvik eden ve ödüllendiren iklimlerden faydalanabilir.

Çevresel uygulamaların benimsenmesi, çalışanların çevresel bilgi ve farkındalıklarını artıracak (Alonso-Almeida vd., 2017) ve bu da yeşil davranışlarını ve isteklerini motive edecektir (Chan vd., 2014). Araştırmada çalışanların çevre dostu davranışları uygulama ve bu davranışlar üzerine olumlu tartışmalar kurarak diğer çalışanları daha fazla çevreye duyarlı olmaları için teşvik etme gibi çevresel farkındalıklarının yüksek olduğu belirlenmiş (Tablo 3) ve bu farkındalığın yüksekliğiyle çalışanlar klima yerine camları açarak serinlemek, elektronik aletleri kullanmadığında güç tasarrufu/uyku moduna alma kapatma veya fişi çekme, şarj edilebilir piller tercih etme ve çevre dostu ürünlere ve çevreye duyarlı davranışlara yönlendirme gibi yeşil davranışları yerine getirdiği bulgulanmıştır. Bu bulgular literatürde yer alan araştırmaların sonuçlarıyla da desteklenmektedir (Tablo 4).

Çevre yanlısı davranış kısa vadede, çevre için daha zararlı olan davranışsal alternatiflerden ziyade daha maliyetlidir (Wagner vd., 2002). Bu nedenle, insanların çoğu zaman çevreye fayda sağlamak için kişisel masraflara maruz kalması gerekir (Steg vd., 2014). Çevre yanlısı davranış, birçok insanın evinde çevre yanlısı davranışlarda bulunmaya istekli ve kendinden motive olduğunu, bunun içinde gerekli masrafları yapmakta istekli olduklarını göstermiştir (Abrahamse vd., 2007; Steg vd., 2014). Araştırmada çalışanların çevreye yardımcı olmak için gönüllü olarak zaman ayırdığı ve para harcadığı görülmüş ve bu şekilde çevreye faydalı olmaktan gurur duyduğu tespit edilmiştir. Bu bulgular literatürde yer alan araştırmaların sonuçlarıyla da desteklenmektedir (Tablo 3).

Sarkis ve ark. (2010) çevre uygulamalarının firma düzeyinde incelemelerinde, çevre uygulamalarında eğitim alan çalışanların firmada çevresel davranışlarda bulunmaya daha istekli olduğunu gözlemlediler. Bu sayede çalışanlar, ekolojik eğitime yapılan yatırımın organizasyonunu istenen davranışlarda bulunarak geri ödedikleri söylenebilir.

Leygue vd., (2017) araştırmada çalışanların yeşil davranışlara teşvik etmenin, çevre yönetim uygulamalarının yerine getirilmesine katkı sağladığı bulgulanmıştır. Wesselink vd., (2017) araştırmalarında, yeşil davranışın veya başka bir deyişle çevre dostu davranmaya yönelik algılanan örgütsel desteğin varlığı çalışanları yeşil davranışları uygulamaya motive ettiğini belirlemiştir.

Phama vd., (2019) 4-5 yıldızlı otel yöneticilerine ve çalışanlarına yönelik yaptığı anket çalışmasının sonucuna göre, eğitim, performans yönetimi ve çalışanların katılımının, çalışanların gönüllü yeşil davranışlarını ve işletmenin çevresel performansını artırabildiğini 
tespit etmiştir. Ratliff vd., (2017) araştırmalarında, çalışanların çevresel faaliyetlere yönelik olumlu ve açık tutumlarının, çevre dostu davranışları benimsemelerini etkilediğini belirlemiştir.

Paille ve Meija-Morelos (2019) çalışmalarında, çevreye yönelik davranışını etkilemede örgütsel desteğin varlığının gerekliğini ve çevreye yönelik örgütsel destek, sınırlı ya da eğilim odaklı olmayan çalışanlar için bireysel çevresel performans üzerinde beklenen etkiyi tetiklemeyebileceğini tespit etmiştir.

Robertson ve Barling (2013) araştırmada, çalışanların çevre yanlısı tutku ve davranışları üzerindeki etkileriyle liderlerin örgütsel yeşillendirme faaliyetini nasıl etkileyebileceğini incelemiş ve öngörüldüğü gibi, çalışanların yeşil davranışlarının çevre tutkusu tarafından etkilendiğini belirlemiştir. Yine Afsar vd., (2016) araştırmada, manevi liderliğin organizasyonel destek aracılığıyla iş yeri maneviyatına, bu değişkenlerinde çevresel tutku ve içsel motivasyon üzerine etkisine ve son olarak bu değişkenlerin hepsinin çevresel davranışlarını nasıl etkileyebileceğini incelemiş ve öngörüldüğü gibi, çalışanların yeşil davranışlarının çevre tutkusu tarafından etkilendiğini belirlemiştir. Araştırmada, çevresel tutkunun yeşil davranışları yerine getirilmesinde önemli bir rol oynadığı tespit edilmiştir ve literatürde yer alan araştırmaların sonuçlarıyla da desteklenmektedir. Bu sonuçlara göre $\mathrm{H} 1$ desteklenmiştir $(\beta=0,77, \mathrm{p}<0,001)$.

2007 yılında Çin hükümeti, kamu birimlerinin ve işletmelerin çevre bilgilerini açıkça ifşa etmeleri gerekliliğine yönelik bir yasa yürüklüğe koymuştur. 2010 yılında Kote Edilen Şirketler İçin Çevresel Bilginin Açıklanması İlkesi, bir kez daha çevreyi çok fazla kirleten sektörlerden olan şirketlerin periyodik olarak çevre bilgilerini paylaşmalarını zorunlu kılmıştır. Çin hükümetinin çalışanların performansını değerlendirmek için kullanılan değerlendirme sistemi, yöneticileri çevre korumayı aktif olarak teşvik etmeye zorlayan güçlü bir araç olmaktadır. Gelişmiş ülkeler ve Türkiye gibi gelişmekte olan ülkelerde bu tür yasalarla çalışanların çevresel davranışlara aktif katılımlarını sağlayabilir.

İşletmeler, çevrenin önemini iletecek şekilde davranarak süreci başlatabilirler. Bu bağlamda çalışanlar, bir kuruluşun çevresel konulardaki uygulamaları ve politikaları gerçekten destek verdiğini (çevresel davranışlarını teşvik ettiği) gördüklerinde çevre konularına daha fazla destek verecektir.

Örneğin işletmeler çalışanların psikolojik ihtiyaçlarını karşılamak için eğitim uygulamalarına yatırımlar yaparak, kişilerarası ve teknik iş becerilerini geliştirecek olumlu bir çalışma ortamı yaratabilir. Özellikle, ödüllendirilme ve çevresel davranışa yönelik eğitim gibi örgütsel davranışlar, çalışanların çevresel davranışlarını etkileyen en önemli uygulamalar olacaktır. Eğitim ve takım oluşturma faaliyetleri sayesinde işletmeler, çalışanlarının beceri setlerini geliştirmeleri ve güvenlik, kabul ve refah duygularını desteklemeleri için teşvik eden koşullar yaratabilir.

Çalışanlar ayrıca, denetçilerin geçmişte çevresel girişimleri nasıl desteklediklerini de dikkate alabilir. Bu bağlamda bu durum, çalışanların çevresel davranışlar için örgütsel destek algısı oluşturmasını sağlar. Ek olarak, eğitim vermek, ödüllendirmek ve çevresel davranışların yönetici tarafından desteklenmesi, çalışanların yeşil davranışlara olan isteğini teşvik edecektir. Çalışanlar bu olumlu duyguyu yaşadıklarında, doğal çevrenin kalitesinde bir fark yaratmak için ilham alacak ve işyerinde çevre ile ilgili davranışlarda bulunmaya motive olacaklardır.

Örneğin, çalışanlar daha az ofis malzemeleri kullanabilir, işyerinde geri dönüşüm yapabilir, araba yerine toplu taşıma araçları kullanabilir, hatta sanal toplantılar düzenleyebilir ya da 
hiç kimse ofiste olmadığında 1şıkları, ısıtmayı ya da aletleri kapatabilirler.

Araştırma, bir çalışanın çevresel aktivizm, sürdürülebilirlik ve korunma konusunda olumlu duyguları varsa çevre yanlısı davranışlarını artırılabileceğini göstermektedir. Sonuç olarak bu araştırma, çalışanların çevre yanlısı davranışlarının sonuçlarının açıklanmasında çevresel tutkunun zorunlu rolünü göstererek literatüre katkı sağlamaktadır.

\section{Kaynakça}

Abrahamse, W., Steg, L., Vlek, C., ve Rothengatter, T. (2007). The effect of tailored information, goal setting, and tailored feedback on household energy use, energy-related behaviors, and behavioral antecedents. Journal of environmental psychology, 27 (4), 265276.

Adams, E.J., Esliger, D.W., Taylor, I.M., ve Sherar, L.B., 2017. Individual, employment and psychosocial factors influencing walking to work: implications for intervention design. PLoS One 12 (2).

Afsar B., Badir Y., Kiani U.S., (2016). Linking spiritual leadership and employee proenvironmental behavior: The influence of workplace spirituality, intrinsic motivation, and environmental passion, Journal of Environmental Psychology ,45, 79-88.

Aizawa, H., Yoshida, H., ve Sakai, S. I. (2008). Current results and future perspectives for Japanese recycling of home electrical appliances. Resources, Conservation and Recycling, 52 (12), 1399-1410.

Alonso-Almeida, M. Del M., Fern.ndez Robin, C., Celem N., Pedroche, M. S., ve Astorga, P. S. (2017). Revisiting green practices in the hotel industry: A comparison between mature and emerging destinations. Journal of Cleaner Production, 140, 1415-1428.

Alt, E., ve Spitzeck, H. (2016). Improving environmental performance through unit-level organizational citizenship behaviors for the environment: A capability perspective. Journal of Environmental Management, 182, 48-58.

Andersson, L., Shivarajan, S., ve Blau, G. (2005). Enacting ecological sustainability in the MNC: a test of an adapted value-belief-norm framework. Journal of Business Ethics, 59, 295-305.

Asilsoy, B. (2012). A survey study on environmental consciousness in Famagusta. ProcediaSocial and Behavioral Sciences, 35, 675-681.

Asilsoy, B., ve Oktay, D. (2016). Environmental attitudes as predictors of ecological citizenship: Findings from a survey in Famagusta, North Cyprus. Open House International (Special Issue on Transformations of Architecture and Urbanism of Cities in the Global South, Eds: A. Salama ve D. Grierson), 41(2), 47-55.

Asilsoy, B., ve Oktay, D. (2018). Exploring environmental behaviour as the major determinant of ecological citizenship. Sustainable cities and society, 39, 765-771.

Bagozzi, R., ve Yi, Y., (1988). On the evaluation of structural equation model. Journal Academic Market Science 16 (1), 74-94.

Barr, S., Ford, N. J., ve Gilg, A. W. (2003). Attitudes towards recycling household waste in Exeter, Devon: quantitative and qualitative approaches. Local Environment, 8 (4), 407-421. 
Berardi, U. (2017). A cross-country comparison of the building energy consumptions and their trends. Resources, Conservation and Recycling, 123, 230-241.

Berry, M. A., ve Rondinelli, D. A. (1998). Proactive corporate environmental management: A new industrial revolution. Academy of Management Perspectives, 12(2), 38-50.

Blok, V., Wesselink, R., Studynka, O., ve Kemp, R. (2015). Encouraging sustainability in the workplace: a survey on the pro-environmental behaviour of university employees. Journal of cleaner production, 106, 55-67.

Boiral, O. (2009). Greening the corporation through organizational citizenship behaviors. Journal of Business Ethics, 87 (2), 221-236.

Carrico, A. R., ve Riemer, M. (2011). Motivating energy conservation at the workplace: an evaluation of the use of group-level feedback and peer education. Journal of Environmental Psychology, 31 (1), 1-13.

Chan, E. S. W., Hon, A. H. Y., Chan, W., ve Okumus, F. (2014). What drives employees' intentions to implement green practices in hotels? The role of knowledge, awareness, concern and ecological behaviour. International Journal of Hospitality Management, 40, $20-28$.

Chou C.J., (2014). Hotels' environmental policies and employee personal environmental beliefs: Interactions and outcomes, Tourism Management, 40, 436-446.

Ciocirlan, C. E. (2017). Environmental workplace behaviors: Definition matters. Organization and Environment, 30 (1), 51-70.

Daily, B. F., Bishop, J. W., ve Govindarajulu, N. (2009). A conceptual model for organizational citizenship behavior directed toward the environment. Business and Society, 48, 243-256.

Daily, B. F., Bishop, J. W., ve Massoud, J. A. (2012). The role of training and empowerment in environmental performance: A study of the Mexican maquiladora industry. International Journal of Operations and Production Management, 32 (5), 631-647.

Danna, K., ve Griffin, R. W. (1999). Health and well-being in the workplace: A review and synthesis of the literature. Journal of Management, 25 (3), 357-584.

Darnall, N., Henriques, I., ve Sadorsky, P. (2008). Do environmental management systems improve business performance in an international setting? Journal of International Management, 14, 364-376.

De Roeck, K., ve Farooq, O. (2017). Corporate social responsibility and ethical leadership: Investigating their interactive effect on employees' socially responsible behavior. Journal of Business Ethics, 151(4), 923-939.

Erbaşı A., (2019). Yeşil Örguitsel Davranış Ölçeği: Bir Ölçek Geliştirme Çalışması, Istanbul Management Journal, 86: 1-23.

Fu, X., Ueland, S. M., ve Olivetti, E. (2017). Econometric modeling of recycled copper supply. Resources, Conservation and Recycling, 122, 219-226. 
Gardner, B., ve Abraham, C. (2010). Going green? modeling the impact of environmental concerns and perceptions of transportation alternatives on decisions to drive. Journal of Applied Social Psychology, 40 (4), 831-849.

Govindarajulu, N., ve Daily, B. F. (2004). Motivating employees for environmental improvement. Industrial Management and Data Systems, 104 (3), 364-372.

Greene, C., Crumbleholme, L., Myerson, J., (2014). Sustainable cultures: engaging employees in creating more sustainable workplaces and workstyles. Facilities 32 (7/8), 438-454.

Gunasekaran, A., ve Gallear, D. (2012). Special Issue on Sustainable development of manufacturing and services. International Journal of Production Economics, 1(140), 1-6.

Junot A., Paquet Y., Martin-Krumm C., (2017). Passion for outdoor activities and environmental behaviors: A look at emotions related to passionate activities, Journal of Environmental Psychology, 53, 177-184.

Lamm, E., Tosti-Kharas, J., ve King, C. E. (2015). Empowering employee sustainability: Perceived organizational support toward the environment. Journal of Business Ethics, 128 (1), 207-220.

Lamm, E., Tosti-Kharas, J., ve Williams, E. G. (2013). Read this article, but don't print it: Organizational citizenship behavior toward the environment. Group and Organization Management, 38 (2), 163-197.

Leygue C., Ferguson E., ve Spence A., (2017). Saving energy in the workplace: Why, and for whom? Journal of Environmental Psychology, 53, 50-62.

Liu, Y., Xing, P., ve Liu, J. (2017). Environmental performance evaluation of different municipal solid waste management scenarios in China. Resources, Conservation and Recycling, 125, 98-106.

Lo, S. H., Peters, G. J. Y., ve Kok, G. (2012). Energy-related behaviors in office buildings: a qualitative study on individual and organisational determinants. Applied Psychology, 61 (2), 227-249.

López-Mosquera, N., Lera-López, F., \& Sánchez, M. (2015). Key factors to explain recycling, car use and environmentally responsible purchase behaviors: a comparative perspective. Resources, Conservation and Recycling, 99, 29-39.

Masri, H. A., ve Jaaron, A. A. (2017). Assessing green human resources management practices in Palestinian manufacturing context: An empirical study. Journal of cleaner production, 143, 474-489.

NAEM (2009). "Advancing Sustainability: Putting Your Employees to Work," http://greentie.naem.org/ 2009/05/12/advancing-sustainability-putting-youremployees-towork.

Paille P., ve Meija-Morelos J.H., (2019). Organisational support is not always enough to encourage employee environmental performance. The moderating role of exchange ideology. Journal of Cleaner Production, 220, 1061-1070.

Paille, P., Boiral, O., ve Chen, Y., (2013). Linking environmental management practices and organizational citizenship behaviour for the environment: a social exchange perspective. Int. J. Hum. Resour. Manag. 24 (18), 3552-3575. 
Paille, P., Mejía-Morelos, J. H., Marche-Paille, A., Chen, C. C., ve Chen, Y. (2016). Corporate greening, exchange process among co-workers, and ethics of care: An empirical study on the determinants of pro-environmental behaviors at coworkers-level. Journal of Business Ethics, 136 (3), 655-673.

Papagiannakis, G., ve Lioukas, S. (2012). Values, attitudes and perceptions of managers as predictors of corporate environmental responsiveness. Journal of environmental management, 100, 41-51.

Phama N.T., Tučkov Z., ve Jabbour C.J.C., (2019). Greening the hospitality industry: How do green human resource management practices influence organizational citizenship behavior in hotels? A mixed-methods study. Tourism Management, 72, 386-399.

Pinzone, M., Guerci, M., Lettieri, E., ve Redman, T. (2016). Progressing in the change journey towards sustainability in healthcare: The role of "Green" HRM. Journal of Cleaner Production, 122, 201-211.

Porter, M., ve Van der Linde, C. (1995). Green and competitive: ending the stalemate. The Dynamics of the eco-efficient economy: environmental regulation and competitive advantage, 33 .

Raineri, N., ve Paille., P. (2016). Linking corporate policy and supervisory support with environmental citizenship behaviors: The role of employee environmental beliefs and commitment. Journal of Business Ethics, 137(1), 129-148.

Ramayah, T., Lee, J. W. C., ve Mohamad, O. (2010). Green product purchase intention: Some insights from a developing country. Resources, conservation and recycling, 54 (12), 14191427.

Ramus, C. A., ve Killmer, A. B. (2007). Corporate greening through prosocial extrarole behaviours-a conceptual framework for employee motivation. Business Strategy and the Environment, 16 (8), 554-570.

Ramus, C. A., ve Steger, U. (2000). The roles of supervisory support behaviors and environmental policy in employee eco-initiatives at leading-edge European companies. Academy of Management Journal, 43, 605-626.

Ratliff K.A., Howell J.L., ve Redford L., (2017). Attitudes toward the prototypical environmentalist predict environmentally friendly behavior, Journal of Environmental Psychology, 51, 132-140.

Ren, S., Tang, G., ve Jackson, S. E. (2017). Green human resource management research in emergence : A review and future directions. Asia Pacific Journal of Management, 1-35.

Robertson, J. L., ve Barling, J. (2013). Greening organizations through leaders' influence on employees' pro-environmental behaviors. Journal of organizational behavior, 34 (2), 176194.

Russell, S., ve Griffiths, A. (2008). The role of emotions in driving workplace proenvironmental behaviors. Research on Emotion in Organizations, 4, 83-107.

Saifulina, N., ve Carballo-Penela, A. (2017). Promoting sustainable development at an organizational level: An analysis of the drivers of workplace environmentally friendly behaviour of employees. Sustainable Development, 25 (4), 299-310. 
Sarkis, J., Gonzalez-Torre, P., ve Adenso-Diaz, B. (2010). Stakeholder pressure and the adoption of environmental practices: The mediating effect of training. Journal of Operations Management, 28 (2), 163-176.

Steg, L., Bolderdijk, J. W., Keizer, K., ve Perlaviciute, G. (2014). An integrated framework for encouraging pro-environmental behaviour: The role of values, situational factors and goals. Journal of Environmental psychology, 38, 104-115.

Steg, L., ve Vlek, C. (2009). Encouraging pro-environmental behaviour: an integrative review and research agenda. Journal of Environmental Psychology, 29 (3), 309-317.

Stern, P. C. (2000). Toward a coherent theory of environmentally significant behavior. Journal of Social Issue, 56 (3), 407-424.

Sun Y., Song J., ve Song D., (2012). An empirical study on influecing factors of residents environmental behavior. Chinese Journal of Management, 9 (1), 144-150.

Temminck, E., Mearns, K., ve Fruhen, L. (2015). Motivating employees towards sustainable behaviour. Business Strategy and the Environment, 24(6), 402-412.

Tsai, C. C., Stritch, J. M., ve Christensen, R. K. (2016). Eco-helping and eco-civic engagement in the public workplace. Public Performance and Management Review, 40 (2), 336-360.

Vallerand, R. J., Blanchard, C. M., Mageau, G. A., Koestner, R., Ratelle, C. F., Léonard M., ve Marsolais, J. (2003). Les passions de l'âme: On obsessive and harmonious passion. Journal of Personality and Social Psychology, 85, 756-767.

Vallerand, R. J., Salvy, S. J., Mageau, G. A., Elliot, A. J., Denis, P. I., Grouzet, F. M. E., ve Blanchard, C. (2007). On the role of passion in performance. Journal of Personality, 75, 505-533.

Wagner, M. (2011). Environmental management activities and sustainable HRM in German manufacturing firms-incidence, determinants, and outcomes. German Journal of Human Resource Management, 25(2), 157-177.

Wagner, M., Van Phu, N., Azomahou, T., ve Wehrmeyer, W. (2002). The relationship between the environmental and economic performance of firms: an empirical analysis of the European paper industry. Corporate social responsibility and Environmental Management, 9(3), 133-146.

Wang, Z., Guo, D., ve Wang, X. (2016). Determinants of residents'e-waste recycling behaviour intentions: evidence from China. Journal of cleaner production, 137, 850-860.

Wesselink R., Blok V., ve Ringersma J., (2017). Pro-environmental behaviour in the workplace and the role of managers and organization, Journal of Cleaner Production, 168, 1679-1687.

Whitmarsh Lorraine ve O'Neill Saffron (2010). Green identity, green living? The role of proenvironmental self-identity in determining consistency across diverse pro-environmental behaviours, Special Issue of the Journal of Environmental Psychology, 1-41. 